\title{
Anti- $N$-methyl-D-aspartate receptor encephalitis 8 years after serial herpes simplex virus type 1 and human herpesvirus type 7 encephalitis
}

\author{
Yoonhyuk Jang*, Jeong-Min Kim*, Jangsup Moon, Kyung-II Park, Soon-Tae Lee, Keun-Hwa Jung, Sang Kun Lee, \\ Kon Chu \\ Department of Neurology, Laboratory for Neurotherapeutics, Comprehensive Epilepsy Center, Seoul National University Hospital, Seoul, \\ Korea
}

Anti- $N$-methyl-D-aspartate receptor (NMDAR) encephalitis is triggered by herpesvirus encephalitis. Human herpesvirus type 7 (HHV-7) is a recently described herpesvirus for which neuroinvasion has been reported rarely. We report a case of anti-NMDAR encephalitis detected 8 years after recurrent herpes encephalitis associated with herpes simplex virus type 1 and HHV-7 in an immunocompetent host. Our case suggests that anti-NMDAR encephalitis may be triggered by HHV-7 meningoencephalitis in immunocompetent adults, and patients with a history of herpesvirus encephalitis should be vigilantly monitored.

Keywords: Herpes simplex virus 1, Human herpesvirus 7, Encephalitis, Foscarnet, Anti-N-methyl-D-aspartate receptor encephalitis

\section{Introduction}

Anti- $N$-methyl-D-aspartate receptor (NMDAR) encephalitis is the most common disease among autoimmune encephalitis. Most patients are female, and ovarian teratoma is a source of autoantibody among $40 \%$ of patients [1]. However, for male and female patients without teratoma, the mechanism of breakdown of immune tolerance to NMDAR is unclear. It has been suggested that direct damage to the central nervous system (CNS) through viral infection could be the origin of the autoantigen, and previous studies have shown that herpesvirus infection can precede anti-NMDAR encephalitis [2-4].

Herpesviruses are large, double-stranded DNA viruses, of which eight human herpesviruses have been identified [5]. They are mostly neurotrophic, sometimes causing serious neurological manifestations either by primary infection or secondary activa- tion [5]. Human herpesvirus type 7 (HHV-7) is a recently described herpesvirus that is ubiquitous and mostly acquired in childhood [6]. Primary infection usually occurs in infants, and symptoms vary from a nonspecific high fever to exanthem subitum [6]. Very little is known of HHV-7 infection in the CNS of immunocompetent hosts, but there have been a few case reports describing HHV-7 neuroinvasion [7-9].

Here, we describe a 32-year-old man who developed anti-NMDAR encephalitis after recurrent herpesvirus meningoencephalitis. Written informed consent was obtained for publication of this case report and accompanying images.

\section{Case Report}

Event 1. Herpes simplex virus type 1 encephalitis A 32-year-old man was admitted due to fever, headache, and al-

Received: November 23, 2020 Revised: December 1, 2020 Accepted: December 2, 2020

Correspondence: Kon Chu

Department of Neurology, Seoul National University Hospital, 101 Daehak-ro, Jongno-gu, Seoul 03080, Korea

E-mail: stemcell.snu@gmail.com

ORCID: https://orcid.org/0000-0001-5863-0302

*These authors contributed equally to this work as co-first authors.

Copyright (C) 2021 by The Korean Encephalitis and Neuroinflammation Society

This is an open access article distributed under the terms of the Creative Commons Attribution Non-Commercial License (http://creativecommons.org/licenses/by-nc/4.0/) which permits unrestricted non-commercial use, distribution, and reproduction in any medium, provided the original work is properly cited. 
tered mental status. He was previously healthy and had no recent history of travel. A cerebrospinal fluid (CSF) study revealed pleocytosis showing $68 / \mathrm{mm}^{3}$ of white blood cells with lymphocyte dominance $(75 \%)$ and mildly elevated protein $(58 \mathrm{mg} / \mathrm{dL})$ (Table 1). Brain magnetic resonance imaging (MRI) showed bilateral asymmetric hyperintense lesions on T2-weighted images, with a mass effect involving both insulas, the hippocampus, lingual gyrus, and left anterior temporal area. A polymerase chain reaction (PCR) study was performed for herpes simplex virus type 1 (HSV-1) and HSV-2 in the CSF specimen and revealed a positive result for HSV-1 DNA. No other viral gene studies were performed. The patient was diagnosed with HSV-1 encephalitis and received acyclovir at a dose of $500 \mathrm{mg}$ intravenous (IV) every 8 hours. After 20 days of treatment, he was discharged without symptoms.

\section{Event 2. HHV-7 encephalitis}

One month after discharge, the patient complained of visual hallucination and agitation and showed aggressive behavior. He was readmitted to the hospital, and a CSF study disclosed 18/ $\mathrm{mm}^{3}$ of white blood cells (Table 1), with HSV-1 DNA detected by PCR. He received acyclovir $500 \mathrm{mg}$ IV every 8 hours for 1 month, but his symptoms worsened to drowsy mental status with no response to verbal stimuli and intermittent oral automatism. Body temperature was high at $37.6^{\circ} \mathrm{C}$. The follow-up CSF study showed $14 / \mathrm{mm}^{3}$ of white blood cells, no red blood cells, $25 \mathrm{mg} /$ $\mathrm{dL}$ of protein, and $77 \mathrm{mg} / \mathrm{dL}$ of glucose (serum glucose, $97 \mathrm{mg}$ / dL) (Table 1). Video-electroencephalogram (EEG) monitoring detected intermittent semirhythmic delta waves in the right temporal area. Brain MRI showed increased extent of the T2 hyperintense lesion, which was more prominent at the left side, at the bilateral temporal lobes, and positron emission tomography revealed profound hypometabolism in the left temporal lobe (Figure 1A and C). Viral gene PCR was used to evaluate HSV-1, HSV-2, varicella-zoster virus, Epstein-Barr virus, cytomegalovirus, HHV-6, and HHV-7. All tests were negative except that for HHV-7 DNA, which was strongly positive in the CSF specimen. Thus, the patient received foscarnet of 2,000 mg IV every 8 hours for HHV-7 encephalitis. After 2 weeks of treatment, he recovered from the drowsy mental state and no longer showed oral automatism or aggressive behavior. Brain MRI showed clear improvement (Figure 1B), and follow-up EEG indicated resolution of the intermittent rhythmic delta slowing in the right temporal area. He was discharged with mild short-term memory decline with instruction to maintain oxcarbazepine of $1,200 \mathrm{mg} /$ day and levetiracetam of $1,000 \mathrm{mg} /$ day.

\section{Event 3. Anti-NMDAR encephalitis}

The patient had no symptom recurrence, even after tapering of the antiepileptic drug oxcarbazepine to $900 \mathrm{mg} /$ day. Eight years later, however, seizure recurred with severe headache and auditory hallucinations. Thorough evaluation was repeated, including viral gene PCR and autoantibody tests. All viral gene PCR evaluations were negative, but anti-NMDAR antibody was detected in serum (Table 1). Immunotherapy with IV immunoglobulin and rituximab was planned for the patient. After four cycles of rituximab treatment, his symptoms improved, and he has had no seizure during four years of follow-up.

\section{Polymerase chain reaction}

Nucleic acid was prepared from cell pellets of CSF or peripheral blood mononuclear cells using the QIAamp DNA Blood Mini Kit (Qiagen, Crawley, UK) following the manufacturer's instruc-

Table 1 Cerebrospinal fluid profiles

\begin{tabular}{|c|c|c|c|c|}
\hline & Day 1 & Day 44 & Day 84 & Eight years later \\
\hline Status & Initial manifestation & Relapse & Aggravation & Relapse \\
\hline Symptom & Headache, fever, drowsy mentality & Abnormal behavior, visual hallucination & Drowsy mentality & Seizure, headache, auditory hallucinations \\
\hline \multicolumn{5}{|l|}{ CSF study } \\
\hline $\mathrm{RBC}(/ \mu \mathrm{L})$ & 4 & $1,020^{\mathrm{b})}$ & 0 & NA \\
\hline WBC $(/ \mu \mathrm{L})$ & 68 & 18 & 14 & NA \\
\hline Protein $(\mathrm{mg} / \mathrm{dL})$ & 58 & 52 & 25 & NA \\
\hline Glucose (mg/dL) & 60 & 62 & 77 & NA \\
\hline $\mathrm{PCR}^{\mathrm{a})}$ & HSV-1(+) & HSV-1(+) & HSV-1(-), HHV-7(+) & HSV-1(-), HHV-7(-) \\
\hline Autoantibody & NA & NA & NA & Anti-NMDAR antibody (+) \\
\hline Treatment & Acyclovir $500 \mathrm{mg}$ & Acyclovir $500 \mathrm{mg}$ & Foscarnet & Rituximab \\
\hline Response & Recovered & No response & Recovered & Recovered \\
\hline
\end{tabular}

CSF, cerebrospinal fluid; RBC, red blood cell; WBC, white blood cell; PCR, polymerase chain reaction; HSV-1, herpes simplex virus type 1; HHV-7, human herpesvirus type 7 ; NA, not available.

${ }^{a)}$ Only HSV-1 and 2 DNA were examined in the first two lumbar puncture studies.

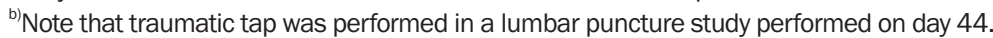


Figure 1 Brain images of human herpesvirus type 7 encephalitis
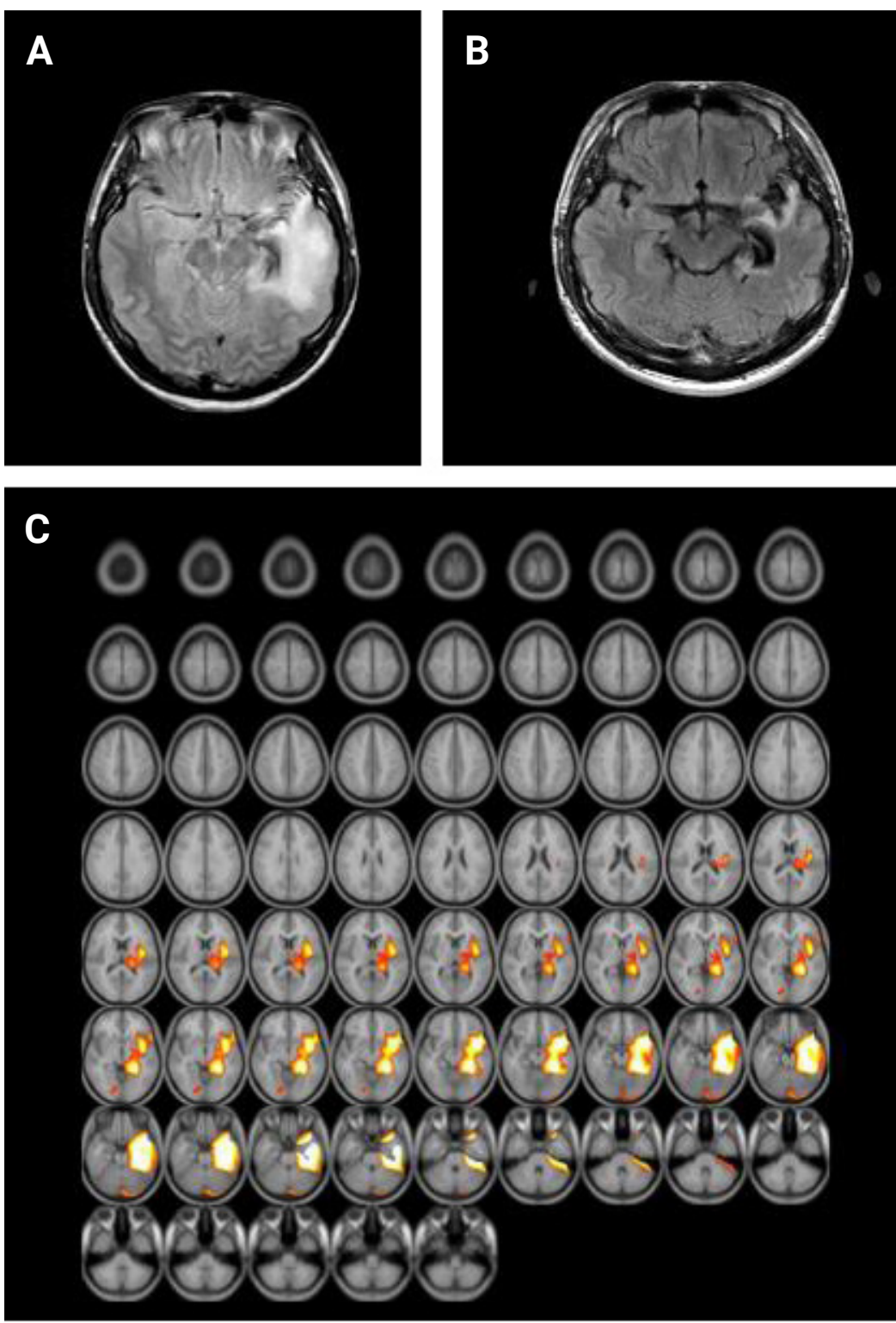

(A) Fluid-attenuated inversion recovery shows high signal intensity, more prominent on the left side, at the bilateral temporal lobes. (B) The lesions regressed after foscarnet treatment. (C) Positron emission tomography with statistical parametric mapping analysis reveals profound hypometabolism in the left temporal lobe.

tions. We performed nested PCR using $15 \mathrm{~L}$ of nucleic acid from serum or CSF. The sequences of the outer pair of primers were TAT CCC AGC TGT TTT CAT ATA GTA AC and GCC TTG CGG TAG CAC TAG ATT TTT TG, and the sequences of the inner pair of primers were CAG AAA TGA TAG ACA GAT GTT GG and TAG ATT TTT TGA AAA AGA TTT AAT AAC. The PCR products were compared by electrophoresis on $2.5 \%$ agarose gels containing ethidium bromide. Positive results were confirmed by repeated tests.

\section{Antibody determination}

Anti-NMDAR antibody was confirmed with two methods, as described previously [10]. These methods were serum and CSF assays with immunostaining of rat brain sections and a cell-based immunochemistry kit (Euroimmun AG, Lübeck, Germany). Antibodies against the contactin-associated protein-like 2 (CASPR2), the leucine-rich glioma-inactivated 1 (CASPR2) receptor, anti- $\alpha$-amino-3-hydroxy-5-methyl-4isoxazolepropionic acid 1 (AMPA1), AMPA2, and $\gamma$-aminobutyr- 
ic-acid type B (GABA-B) receptors were negative, as were antibodies against $\mathrm{Hu}, \mathrm{Yo}, \mathrm{Ri}, \mathrm{Ma} 2, \mathrm{CV} 2$, amphiphysin, recoverin, Soxl, and titin antibodies.

\section{Discussion}

Our case illustrates recurrent meningoencephalitis associated with HSV-1, HHV-7, and subsequent anti-NMDAR encephalitis in an immunocompetent adult host. After HHV-7 had been treated with foscarnet, the patient's drowsy mental state significantly improved, along with cessation of nonconvulsive seizures. Follow-up brain MRI and EEG showed findings consistent with resolution of encephalitis, including absence of active lesions and epileptic activity, respectively. The seizure relapse 8 years later led to detection of anti-NMDAR encephalitis, and the patient was treated with immunotherapy.

In the present case, HHV-7 could be associated with recurrent encephalitis after the first HSV-1 infection had been sufficiently treated by acyclovir. The causative agent for the initial event could have been HSV-1, considering the bilateral temporal lobar involvement demonstrated on brain MRI and detection of HSV1 DNA by PCR. Recurrent encephalitis in HSV-1 infection is occasionally reported and is related with severity of the first infection [5]. Because the initial viral DNA studies examined only HSV-1 and HSV-2, it is unclear whether HHV-7 initially coinfected the patient or if he was infected later. Nonetheless, a later CSF study revealed a negative result for HSV-1 DNA and a positive result for HHV-7 DNA, suggesting involvement of HHV-7 infection in the second episode of encephalitis.

Furthermore, dramatic symptom relief after foscarnet treatment supports the idea that HHV-7 was related to the recurrent encephalitis in our case. Although there are no treatment guidelines or randomized clinical trials for HHV-7 infection, foscarnet or ganciclovir is recommended as a therapeutic option because HHV-7 is resistant to acyclovir [7]. On the other hand, acyclovir, which must be phosphorylated by virus-encoded kinases to retain antiviral activity, is an effective antiviral agent against HSV-1 and HSV-2 [11]. Foscarnet and its analogues achieve their antiviral effects via inhibition of viral polymerases, without activation or phosphorylation of the compounds by viral or cellular proteins [12]. Therefore, they have shown effective antiviral activity against acyclovir-resistant herpes simplex infection and herpesviruses such as HHV-7 [11,13].

In the present case, the autoimmune encephalitis was identified 8 years after serial herpesvirus encephalitis, and the symptoms might have been too mild to be detected before the infection was identified. Whether the NMDAR antibody was present at the time of HHV-7 infection is unclear; NMDAR-autoantibody detection was not available in 2007 when there was no concept of anti-NMDAR encephalitis [14]. Moreover, we do not know whether HSV-1 infection or HHV-7 infection resulted in breakdown of immune tolerance to NMDAR. According to the hypothesis that CNS damage triggers autoimmunity by exposure of NMDARs [4], either herpesviruses could be the cause of the patient's anti-NMDAR encephalitis. Our result implies that HHV-7 infection, which is ubiquitous and generally asymptomatic, can be the origin of autoimmunity for patients with anti-NMDAR encephalitis who have no teratoma. Thus, development of anti-NMDAR encephalitis should be vigilantly monitored in patients with a history of herpes virus encephalitis. Conversely, in patients with anti-NMDAR encephalitis who have no teratoma, herpes viral infection history should be carefully investigated.

In summary, we report a case of recurrent herpesvirus encephalitis followed by anti-NMDAR encephalitis in an immunocompetent young man. This report furthers our knowledge about the clinical manifestations of rare HHV-7 infection and suggests that anti-NMDAR encephalitis can be identified years after herpes virus infection.

\section{Conflicts of Interest}

Jangsup Moon, Kyung-Il Park, Soon-Tae Lee, Keun-Hwa Jung, Sang Kun Lee, Kon Chu have been editorial board of encephalitis since October 2020. They were not involved in the review process of this case report. No other potential conflict of interest relevant to this article was reported.

\section{Author Contributions}

Conceptualization: Chu K; Investigation: Kim JM, Moon J, Chu K; Data curation: Jang Y, Kim JM; Formal analysis: Lee ST; Resources, Funding acquisition: Park KI, Jung KH, Chu K, Lee SK; Supervision: Chu K; Writing-original draft: Jang Y, KimJM; Writing-review and editing: all authors.

\section{Acknowledgements}

This work was supported by the Ministry of Health and Welfare (grant No. A060452), Republic of Korea. 


\section{References}

1. Dalmau J, Graus F. Antibody-mediated encephalitis. N Engl J Med 2018;378:840-851.

2. Leypoldt F, Titulaer MJ, Aguilar E, et al. Herpes simplex virus-1 encephalitis can trigger anti-NMDA receptor encephalitis: case report. Neurology 2013;81:1637-1639.

3. Salovin A, Glanzman J, Roslin K, Armangue T, Lynch DR, Panzer JA. Anti-NMDA receptor encephalitis and nonencephalitic HSV-1 infection. Neurol Neuroimmunol Neuroinflamm 2018;5:e458.

4. Armangue T, Leypoldt F, Málaga I, et al. Herpes simplex virus encephalitis is a trigger of brain autoimmunity. Ann Neurol 2014;75:317-323.

5. Gilden DH, Mahalingam R, Cohrs RJ, Tyler KL. Herpesvirus infections of the nervous system. Nat Clin Pract Neurol 2007;3:82-94.

6. Levy JA. Three new human herpesviruses (HHV6, 7, and 8). Lancet 1997;349:558-563.

7. van den Berg JS, van Zeijl JH, Rotteveel JJ, Melchers WJ, Gabreëls FJ, Galama JM. Neuroinvasion by human herpesvirus type 7 in a case of exanthem subitum with severe neurologic manifestations. Neurology 1999;52:1077-1079.

8. Ward KN, Kalima P, MacLeod KM, Riordan T. Neuroinvasion during delayed primary HHV-7 infection in an immunocompetent adult with encephalitis and flaccid paralysis. J Med Virol 2002;67:538-541.

9. Mihara T, Mutoh T, Yoshikawa T, Yano S, Asano Y, Yamamoto H. Postinfectious myeloradiculoneuropathy with cranial nerve involvements associated with human herpesvirus 7 infection. Arch Neurol 2005; 62:1755-1757.

10. Lee WJ, Lee ST, Byun JI, et al. Rituximab treatment for autoimmune limbic encephalitis in an institutional cohort. Neurology 2016;86: 1683-1691.

11. De Clercq E, Naesens L, De Bolle L, Schols D, Zhang Y, Neyts J. Antiviral agents active against human herpesviruses HHV-6, HHV-7 and HHV-8. Rev Med Virol 2001;11:381-395.

12. Crumpacker CS. Mechanism of action of foscarnet against viral polymerases. Am J Med 1992;92:3S-7S.

13. Dewhurst S. Human herpesvirus type 6 and human herpesvirus type 7 infections of the central nervous system. Herpes 2004;11 Suppl 2: 105A-111A.

14. Dalmau J, Gleichman AJ, Hughes EG, et al. Anti-NMDA-receptor encephalitis: case series and analysis of the effects of antibodies. Lancet Neurol 2008;7:1091-1098. 
